\section{IN THE NEWS}

Stress can be good for you It has long been known that stress can have a negative effect on the immune system. But new research reported

in the July issue of

Psychological Bulletin indicates that short bursts of stress boost the immune system, and only chronic stress is associated with global immunosuppression

Suzanne Segerstrom and Gregory Miller used data from 293 previously published independent studies to analyse the effect of various stressors on different immune responses. By using this approach, known as metaanalysis, they were able to

"...ask questions that are too big for any one study to answer" and "... see if things are consistent over the gamut of labs, methods and people." (American Psychological Association, online.) Several clear patterns emerged from the analysis: first, short term stressors, such as public speaking, which induce the 'flight or fight' response, enhanced natural immunity; second, chronic stressors, such as becoming permanently disabled, were associated with decreased immune function; and third, these stress-related changes in immune function were more likely to affect the elderly and sick.

According to Phillip Hodson of the British Association for Counselling and

Psychotherapy, these results make sense. He says, "We all need some pressure in life. Stress is there to make sure you do your best in a challenging situation .. What's damaging health wise is unrelieved stress" (The Times).

These findings are particularly relevant to the lifestyle of many people today. In a recent survey carried out by the Chartered Institute of Personnel and Development (CIPD), it was noted by Ben Willmott of the CIPD that "The most significant finding of the study has been the increase in stress-related absence [from work]" (The Times).

Karen Honey

\title{
B CELLS
}

\section{MITF's calming influence}

Some of the transcription factors that promote the differentiation of B cells into plasma cells (BLIMP1, $\mathrm{XBP} 1$ and interferon-regulatory factor $4, \mathrm{IRF} 4)$ or antagonize this developmental step in germinalcentre B cells (PAX5) have been identified. However, whether similar regulation of differentiation occurs in naive B cells is unclear. Now, a study published in The Journal of Experimental Medicine has identified the microphthalmia-associated transcription factor (MITF) as a negative regulator of plasma-cell differentiation in these cells.

Using data previously generated by microarray analysis, Lin et al. observed that Mitf cDNA was expressed by resting but not activated B cells,

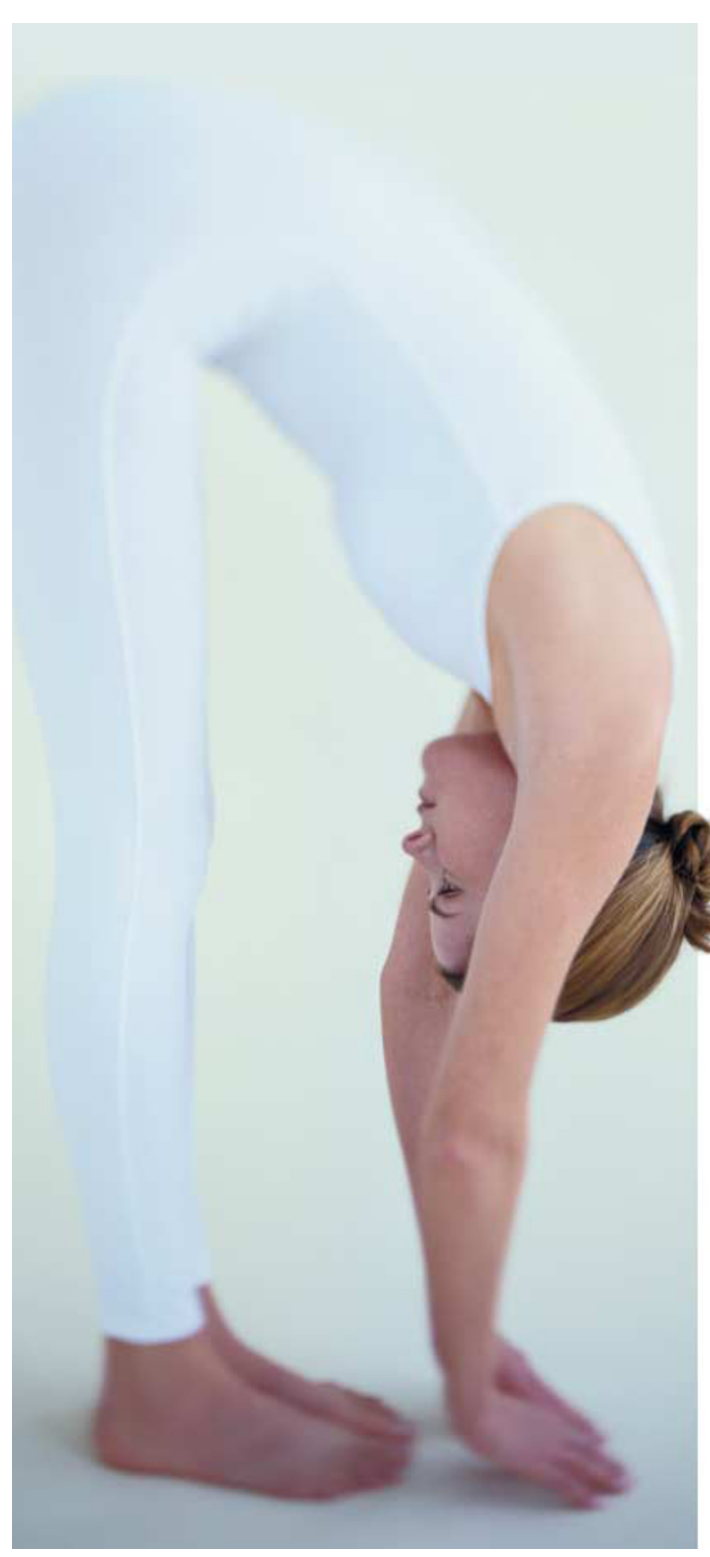

indicating that it could be a novel B-cell transcription factor. MITF exists as distinct isoforms that are expressed in a tissue-specific manner. These isoforms share exons 2-9 and are distinguished solely by differential first-exon usage. In this investigation, B-cell expressed MITF was shown to be encoded by the common exons and two rarely studied exons (exons 1a and $1 \mathrm{~b}$ ), so it corresponded to a previously described isoform of MITF, MITF-A.

Mice that lack functional MITF protein - $m i / m i$ mice - have several developmental defects, so the role of MITF specifically in B-cell development was studied by transferring bone marrow from wild-type or $\mathrm{mi} / \mathrm{mi}$ animals into recombination-activating gene 2-deficient hosts. B-cell development occurred normally in recipients of $\mathrm{mi} / \mathrm{mi}$ bone marrow; however, these animals had increased levels of serum IgM, as well as increased numbers of splenic $\mathrm{CD} 138^{+} \mathrm{B} 220^{-}$plasma cells and IgM-secreting cells. Together with the observation that T-cell-dependent and T-cellindependent antibody responses were comparable in wild-type and $\mathrm{mi} / \mathrm{mi}$ bone-marrow recipients, these results indicate that $\mathrm{mi} / \mathrm{mi} \mathrm{B}$ cells are not hyperactive as such but undergo spontaneous differentiation into plasma cells in vivo. Consistent with this, $\mathrm{mi} / \mathrm{mi} \mathrm{B}$ cells cultured in the absence of stimulation secreted increased amounts of IgM and upregulated expression of the plasma-cell marker CD138.

Further evidence of a role for MITF in suppressing plasma-cell differentiation was provided by gainof-function studies - activated wild-type B cells retrovirally transduced to express MITF were markedly impaired in their ability to upregulate CD138 and to secrete IgM. This MITF-induced block in plasma-cell differentiation was associated with decreased levels of IRF4. Conversely, $\mathrm{mi} / \mathrm{mi}$ B cells were shown to express increased levels of IRF4. The importance of these observations was demonstrated by showing that spontaneous IgM secretion by $\mathrm{mi} / \mathrm{mi}$ $B$ cells was abrogated by antisense oligonucleotide blockade of IRF4.

This study identifies MITF as a novel regulator of B-cell differentiation, which functions as a suppressor of spontaneous differentiation of naive B cells into plasma cells by inhibiting IRF4 expression. Further studies are required to define how MITF mediates IRF4 inhibition; however, as the authors were unable to detect MITF binding to the Irf4 promoter, it is probable that other transcription factors are involved.

Karen Honey

(D) References and links

ORIGinal ReSEARCH PAPER Lin, L., Gerth, A. J. \& Peng, S. L. Active inhibition of plasma cell development in resting $B$ cells by microphthalmiaassociated transcription factor. J. Exp. Med. 200, 115-122 (2004). WEB SITE

Stanford Peng's lab: http://dbbs.wustl.edu/dbbs/website.nsf/FA A6CE14EDC5BDFDDB86256D4E005B2D8A?OpenDocument 